\title{
BMJ Open Relationship of altitude mountain sickness and smoking: a Catalan traveller's cohort study
}

\author{
Alba Sánchez-Mascuñano, Cristina Masuet-Aumatell, Sergio Morchón-Ramos, \\ Josep M Ramon
}

To cite: Sánchez-Mascuñano A, Masuet-Aumatell C, MorchónRamos S, et al. Relationship of altitude mountain sickness and smoking: a Catalan traveller's cohort study. BMJ Open 2017;7:e017058. doi:10.1136/ bmjopen-2017-017058

- Prepublication history for this paper is available online. To view these files please visit the journal online (http://dx.doi. org/10.1136/bmjopen-2017017058).

Received 29 March 2017 Revised 29 May 2017 Accepted 30 June 2017

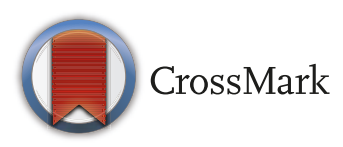

Department of Preventive Medicine, Bellvitge Biomedical Research Institute (IDIBELL), International Health Center and Travel Medicine Clinic, University Hospital of Bellvitge, L'Hospitalet de Llobregat, Catalonia, Spain

Correspondence to Dr Cristina Masuet-Aumatell; cmasuet@bellvitgehospital.cat

\section{ABSTRACT}

Objectives The aim of this study is to analyse the relationship between smoking and altitude mountain sickness in a cohort of travellers to 2500 metres above sea level (masl) or higher.

Setting Travel Health Clinic at the Hospital Universitari de Bellvitge, in Barcelona, Spain.

Participants A total of 302 adults seeking medical advice at the travel clinic, between July 2012 and August 2014, before travelling to 2500 masl or above, who agreed to participate in the study and to be contacted after the trip were included. Individuals who met the following criteria were excluded: younger than 18 years old, taking carbonic anhydrase inhibitors for chronic use, undergoing treatment with systemic corticosteroids and taking any medication that might prevent or treat altitude mountain sickness (AMS) prior to or during the trip. The majority of participants were women $(n=156,51.7 \%)$. The mean age was 37.7 years (SD 12.3). The studied cohort included 74 smokers (24.5\%), 158 (52.3\%) non-smokers and $70(23.2 \%)$ ex-smokers. No statistical differences were observed between different sociodemographic characteristics, constitutional symptoms or drug use and smoking status.

Outcomes The main outcome was the development of AMS, which was defined according to the Lake Louise AMS criteria.

Results AMS, according to the Lake Louise score, was significantly lower in smokers; the value was $14.9 \%$, $95 \% \mathrm{Cl}(6.8$ to $23.0 \%)$ in smokers and $29.4 \%, 95 \% \mathrm{Cl}$ $(23.5$ to $35.3 \%)$ in non-smokers with an adjusted $\mathrm{OR}$ of $0.54,95 \% \mathrm{Cl}(0.31$ to 0.97$)$ independent of gender, age and maximum altitude reached.

Conclusions These results suggest that smoking could reduce the risk of AMS in non-acclimated individuals. Further studies should be performed in larger cohorts of travellers to confirm these results. Despite the results, smoking must be strongly discouraged because it greatly increases the risk of cardiorespiratory diseases, cancer and other diseases.

\section{INTRODUCTION}

Every year, millions of tourists travel to high altitude destinations, easily reaching altitudes higher than 2500 metres above sea level (masl), and they usually have no previous acclimatisation, being at risk of altitude

\section{Strengths and limitations of this study}

This study is the first cohort study of travellers going to different high altitude destinations worldwide to evaluate the effect of the smoking status on the risk of AMS. This study provides a profile of travellers going to typical high altitude destinations, with different itineraries and locations, for both genders and different education levels.

- Pretravel data were collected face-to-face, while post-travel was collected through phone and email. Although this could represent a potential limitation, the sensitivity analysis did not show any difference in the results.

- Smoking consumption was described before and after travelling, and no difference was detected; thus, we have to assume that participant consumption was stable, and no change occurred during travel.

> Healthy travellers could be more prone to reach higher altitudes than travellers with health conditions. This could lead to selection bias. However, we found no differences in altitude reached between travellers with or without potentially disabling conditions.

mountain sickness (AMS). Some specific factors such as previous AMS, age or gender are associated with an increase in an individual's likelihood of suffering from AMS during ascent. Physical fitness has not been associated with AMS onset. ${ }^{1-4}$

AMS usually occurs within the initial 6-12 hours after the ascent, at 2500 masl or above. ${ }^{56}$ Its incidence and severity increase with altitude. ${ }^{5} 7$ The symptoms are usually mild and involve headaches and a reduction in physical ability. ${ }^{8}$ For ascents above 4500 masl, and according to previous studies, AMS may appear in between $50 \%$ and $85 \%$ of non-acclimated travellers, and it might be severely debilitating. ${ }^{9}$

The barometric pressure (BP) diminishes at increasing altitude. The oxygen inspiratory proportion is constant at $20.9 \%$, but the oxygen inspiratory pressure $\left(\mathrm{PiO}_{2}\right)$ decreases with increasing $\mathrm{BP}$. This results in a reduction 
of the oxygen's arterial saturation, which eventually reduces the tissues' oxygen supply.

The acute response to an arterial partial pressure of oxygen reduction is hyperventilation and an increased cardiac output. There are notable differences between individuals in the quality of these responses, which do not fully compensate for the drop in $\mathrm{PiO}_{2}$, especially when ascending too rapidly. ${ }^{1011}$

Some hypotheses suggest that smokers would suffer more from AMS than non-smokers because of carboxyhaemoglobin reducing the capacity for oxygen transport, worsening of their hypoxaemia and diminished oxygen uptake from the effect of the smoke on the respiratory system, while others report a reduction in AMS for smokers. ${ }^{12-15}$ Around $30 \%$ of the world's population declare being active smokers, yet there is a notable lack of consensus regarding the relationship between smoking and AMS risk. A recent meta-analysis performed by Vinnikov et $a l^{16}$ showed that there was no significant association between smoking and AMS, while another performed by $\mathrm{Xu}$ et $a l^{17}$ found an association between smoking and AMS, the former being a protective factor. The smoking status of travellers is not routinely explored, potentially resulting in an incomplete or misguided approach in the pretravel advice and treatment they receive. Previous studies of the relationship between smoking and AMS risk have yielded inconsistent findings

The aim of this study was to analyse the relationship between tobacco smoking and the incidence of AMS in individuals travelling to altitudes equal to or above 2500 masl.

\section{MATERIAL AND METHODS \\ Study design}

A prospective cohort study was performed in a travel clinic among individuals who consecutively presented to the clinic and were travelling to high altitude regions and willing to be questioned before and after travel regarding their experience with AMS. The information was gathered through two questionnaires: one that was completed face-to-face prior to the trip and during the medical visit (baseline questionnaire) and another that was completed by phone or email from 7 days after the expected return date (post-travel questionnaire).

\section{Setting}

The study was conducted at the Travel Health Clinic at the Hospital Universitari de Bellvitge, in Barcelona, Spain.

\section{Participants}

Adults seeking medical advice at the travel clinic, between July 2012 and August 2014, before travelling to 2500 masl or above, who agreed to participate in the study and to be contacted after the trip were included. Individuals who met the following criteria were excluded: younger than 18 years old, taking carbonic anhydrase inhibitors for chronic use, undergoing treatment with systemic corticosteroids and taking medication that might prevent or treat AMS prior to or during the trip or acetazolamide. Furthermore, none of the participants took Gingko biloba, or dexamethasone prior to or during the trip, which could have prevented AMS. Phone numbers and email addresses were registered to contact the individuals and conduct the follow-up.

The participation was voluntary, participants were not offered any financial incentive and they were informed about their right to withdraw at any time, without penalty. The institutional ethical review board (University Hospital of Bellvitge) approved the study protocol and informed consent. All participants provided written informed consent.

\section{Variables and instrument}

Both questionnaires were initially tested in several travellers and amended for clarity. To estimate the consistency of the responses, some probe questions were used. The questionnaires were administered by a trained medical doctor face-to-face and by phone or email 7 days after the expected date of return by the same trained medical doctor.

The questionnaires were based on five areas: demographic (age and gender); medical history (comorbidities, pregnancy, current pharmacological treatments, smoking status, number of cigarettes per day, previous exposure to $\geq 2500$ masl and prior AMS history); clinical symptoms that developed at altitude; preventive or therapeutic measures undertaken during travelling (AMS prophylaxis or treatment); travel information (itinerary, country, length, duration of the trip, maximum altitude reached (MAR), daily average ascent, time from arrival at altitude to the onset of AMS and type of ascent).

The main outcome was the development of AMS, which was defined according to the Lake Louise AMS criteria (LL). ${ }^{4}$ The Lake Louise Score includes nine questions about nine different AMS-related symptoms: headache, nausea/vomiting, fatigue, dizziness, sleep disturbances, mental alterations, ataxia, peripheral oedema and activity reduction. The presence and severity of these symptoms is scored from 0 to 3 points for each question. The LL criteria state that an individual is suffering from AMS in the context of a rise in altitude within the last 4 days if the total score is three or more, the individual has a headache and at least one other symptom from the LL. AMS is classified as mild AMS (3-5 points) or severe AMS $(\geq 6$ points). It is validated for use by individuals (patients or travellers) who lack medical training. ${ }^{6}$

The value of MAR was determined through revising each traveller's expected itinerary and checking the altitudes at the Earth Resources Observation Systems Data Center. ${ }^{18}{ }^{19}$ The MAR was dichotomised using the median value (P50), corresponding to 3400 masl.

The value of daily average ascent was determined by reviewing the expected transportation that was supposed to be used at each night stop on the route, providing the altitude drop (in metres) for each day of the route. The 
values were summed and divided by the total number of days on the route for which there is an expected change in altitude.

The smoking status was recorded as self-report and registered as cigarettes per day and categorised as one of the following three categories: non-smoker/ex-smoker/current smoker. ${ }^{20}$ Individuals who had ever smoked (but did not smoke at the time of the interview and at least 3 months before travel) were defined as ex-smokers. Individuals who had never smoked were defined as non-smokers, and individuals who smoked at the time of the interview more than one cigarette per day were defined as smokers. Ex-smokers were treated as non-smokers when they stopped smoking for more than 3 months before the trip because haemoglobin's capacity for oxygen transportation is equal in ex-smokers and non-smokers after 3 months of smoking cessation. ${ }^{9}$

\section{Statistical methods}

A descriptive analysis was conducted to evaluate the sociodemographic characteristics, medical history, clinical symptoms developed at altitude, preventive or therapeutic measures undertaken during travelling and travel information. Quantitative variables that had a normal distribution (Kolmogorov-Smirnov test, $\mathrm{p}>0.05$ ) were expressed as mean and SD, while qualitative variables were measured as percentages. The overall cumulative incidence and stratification by smoking status were estimated with their corresponding 95\% CI. The $\chi^{2}$ test, or Fisher's test (when required), was used for qualitative comparisons. Mean values were compared using Student's t-test, analysis of variance, Mann-Whitney U test or Kruskal-Wallis test when needed and depending on the normality criteria. Finally, a multivariate analysis with a logistic regression model was performed to adjust for potential confounders and estimate the crude and adjusted OR of AMS. In all cases, a $\mathrm{p}$ value $<0.05$ was accepted as statistically significant, and a proper interpretation of the results in context with potential confounders was considered. Statistical analysis was performed with the Statistical Package for the Social Sciences (SPSS) V.17.0 for Windows.

\section{RESULTS}

A total of 302 travellers were included in the study. The reasons for participation refusal were non-operational phone $(n=7)$ or email $(n=6)$, post-travel contact was not possible $(\mathrm{n}=195)$ and lack of time to answer the phone call $(n=5)$ or email $(n=5)$. The individuals were categorised as non-responders when no contact could be made after five phone call attempts, on different times of different weekdays, as well as an email contact attempt. The dropout rates were similar in gender and smoking status $(p>0.05)$.

The majority of participants were women $(n=156$, $51.7 \%$ ), the mean age was 37.7 years (SD 12.3), from high social status $(54.0 \%$ of university studies attained), not taking beta-blockers $(\mathrm{n}=286,94.7 \%)$, thiazide $(\mathrm{n}=275$, $91.0 \%)$, potassium-sparing diuretics $(\mathrm{n}=280,92.7 \%)$,
OCP $(n=16,10.3 \%)$, neither vitamin C $(n=290,96.0 \%)$. The baseline constitutional symptoms prior to going to altitude as migraines or insomnia, chronic pain or gastrointestinal problems were quite similar compared with the general population $(12.9 \%, 5.6 \%, 21.2 \%$ and $7.9 \%$, respectively), and none had a previous AMS history.

According to the smoking status, the majority of participants were non-smokers $(\mathrm{n}=158,52.3 \%)$ followed by ex-smokers $(\mathrm{n}=70,23.2 \%)$. Smokers made up $24.5 \%$ of travellers $(\mathrm{n}=74)$ at a mean age of 35.7 years (SD 11.2), smoking a mean of 12.14 cigarettes per day (SD 6.7) for 13.8 years (SD 5.8). The duration of smoking among regular heavy smokers, light smokers or ex-smokers were similar without statistical differences between them $(p>0.05)$, as the studied population was quite young. No statistical differences were observed between different demographic characteristics, constitutional symptoms or drug use and smoking status ( $>0.05)$ (table 1). Hence, the sensitivity to report constitutional symptoms at altitude on recall after travel could be quite similar between smoking status and prior constitutional symptoms.

The overall incidence of AMS was $25.8 \%$ (95\% CI 20.9 to 30.8 ). Among the travellers who showed symptoms compatible with AMS, 46 individuals (59.0\%) showed symptoms that were compatible with AMS within 12 hours of arrival at altitude, $12(15.4 \%)$ between 12 hours and 24 hours, $8(10.2 \%)$ between 24 hours and 36 hours, $2(2.6 \%)$ between 36 hours and 48 hours and $3(3.8 \%)$ beyond 48 hours from arrival at altitude. The travellers who showed an onset of symptoms at $>48$ hour $(n=3)$ did not show any other symptoms suggestive of other pathological processes; as a result, they were kept in the cohort of AMS-affected individuals. Seven (9.0\%) of the AMS-affected individuals did not report the time of symptom onset. Travellers were asked about other clinical aspects to ensure that the symptoms were linked to altitude.

The majority of AMS-affected individuals had mild AMS $(\mathrm{n}=59,75.6 \%)$ with an LL score median of $4(\mathrm{IQR}=1)$ and presented headaches and sleep disturbances (69.2\%) or nauseas $(65.4 \%)$. The median LL scores of the travellers with AMS were significantly different between non-smokers $\left(5 ; Q_{1}=3.5, Q_{3}=6\right)$ and smokers $\left(3, Q_{1}=3\right.$, $\mathrm{Q}_{3}=3 ; \mathrm{p}=0.045$ ).

The incidence of AMS was higher in non-smokers (29.4\%; 95\% CI 23.5 to 35.3$)$ than in smokers $(14.9 \%$; $95 \%$ CI 6.8 to 23.0$)$, as well as in females $(\mathrm{p}=0.022)$, and travellers who reached higher altitudes $(\mathrm{p}<0.001)$, and there were no differences according to age $(\mathrm{p}=0.165)$ or type of ascent $(\mathrm{p}=0.765)$ (table 2$)$.

According to the multivariate analysis, the risk of suffering AMS for participants who were female was $54 \%$ higher than that for males (adjusted OR (aOR) 1.53, $95 \%$ CI 1.06 to 2.25$), 78 \%$ higher when the traveller reached very high altitudes ( $>3400$ masl) than lower altitudes (aOR 1.78, 95\% CI (1.25 to 2.59)) and $46 \%$ lower if the traveller was a smoker instead of non-smoker (aOR $0.54,95 \% \mathrm{CI}(0.31$ to 0.97$))$ regardless of age, gender and maximum altitude reached (table 3 ). 
Open Access

Table 1 Baseline sample characteristics in global and by smoking status

Smokers $(n=69) \quad$ Never smoker and ex-smokers $(n=233) \quad$ Total $(n=302) \quad p$ Value

\section{Age}

Mean (SD)

Gender (n (\%))

$\begin{array}{llrr}\text { Male } & 35(50.7) & 111(47.6) & 146(48.4) \\ \text { Female } & 34(49.3) & 122(52.4) & 156(51.7)\end{array}$

Educational attainment ( $(\%))$

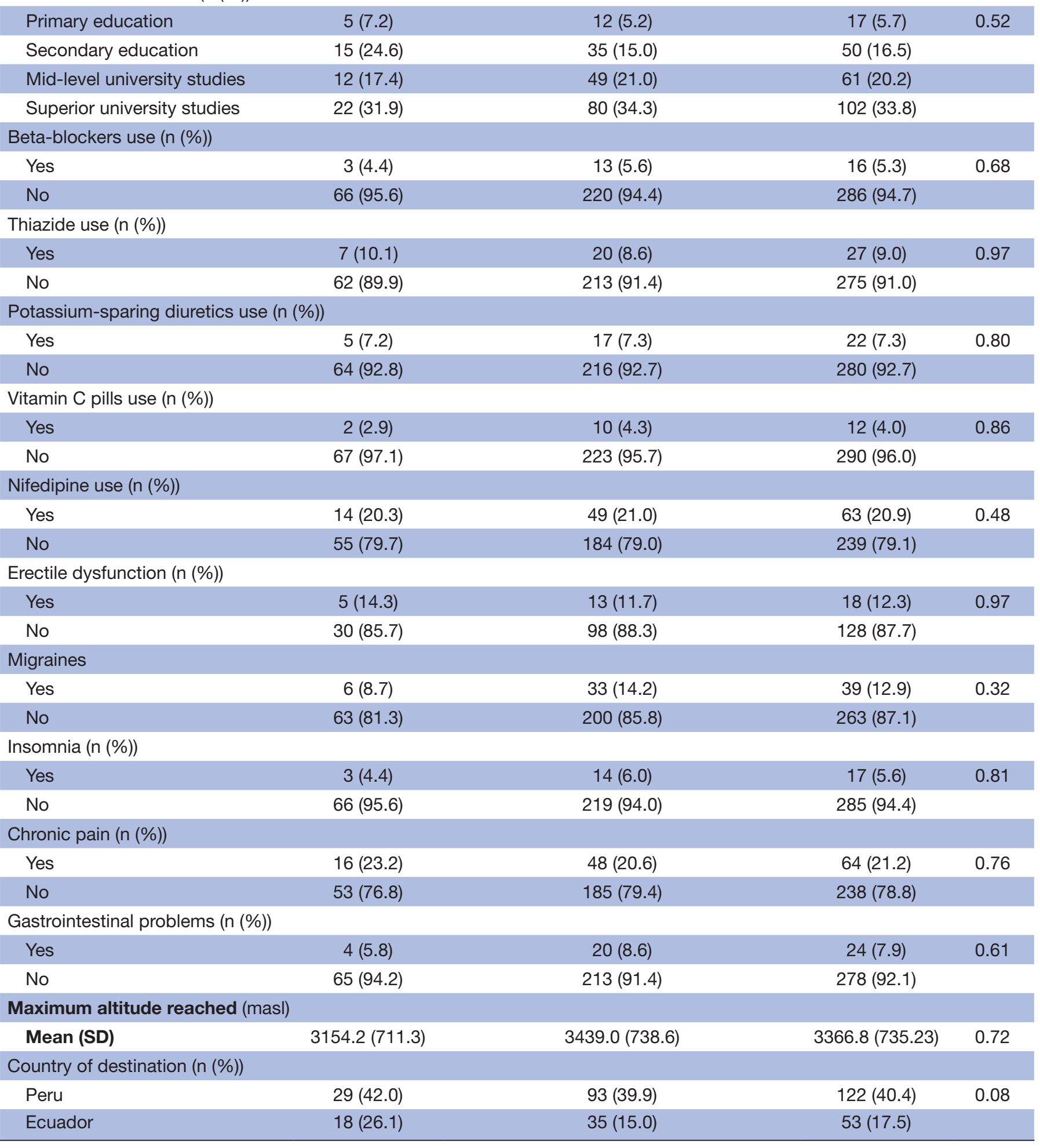

Continued 
Table 1 Continued

\begin{tabular}{|c|c|c|c|c|}
\hline & Smokers $(n=69)$ & Never smoker and ex-smokers $(n=233)$ & Total $(n=302)$ & p Value \\
\hline Colombia & $11(15.9)$ & $35(15.0)$ & $46(15.2)$ & \\
\hline Nepal & $8(11.6)$ & $32(13.7)$ & $40(13.3)$ & \\
\hline Bolivia & $3(4.4)$ & $35(15.0)$ & $38(12.6)$ & \\
\hline Tanzania & $0(1.0)$ & $3(1.0)$ & $3(1.0)$ & \\
\hline \multicolumn{5}{|l|}{ Type of travel (n (\%)) } \\
\hline Organised tourism & $7(10.1)$ & $23(9.9)$ & $30(9.9)$ & 0.99 \\
\hline Free tourism & $27(39.1)$ & $91(39.1)$ & $118(39.1)$ & \\
\hline Work & $4(5.8)$ & $21(9.1)$ & $25(8.3)$ & \\
\hline Visiting friends or relatives & $15(21.7)$ & $53(22.8)$ & $68(22.5)$ & \\
\hline Cooperation & $7(10.1)$ & $25(10.7)$ & $32(10.6)$ & \\
\hline Studying & $1(1.4)$ & $2(0.86)$ & $3(1.0)$ & \\
\hline Trekking & $1(1.4)$ & $4(1.7)$ & $5(1.7)$ & \\
\hline
\end{tabular}

\section{DISCUSSION}

To the best of our knowledge, this study is the first cohort study of travellers going to different high altitude destinations globally to evaluate the effect of the smoking status on the risk of AMS. This study provides a profile of travellers going to typical high altitude destinations, with different itineraries and locations, for both genders and different education levels.

The surveyed population was selected from a Travel Health Clinic, which might have selected for a population from a higher social status compared with the general population, even though we found different travel typologies (organised tourism, non-organised tourism and trekking). Therefore, considering the high social status present in our cohort, our results might have been

Table 2 Frequency of altitude mountain sickness by tobacco consumption, age, gender and maximum altitude reached; univariate analysis $(n=302)$

\begin{tabular}{|c|c|c|}
\hline \multicolumn{3}{|c|}{ Altitude mountain sickness } \\
\hline & n (\%) & p Value \\
\hline Non-smokers & $68(29.2)$ & $0.01^{*}$ \\
\hline Smokers & $10(14.5)$ & \\
\hline \multicolumn{3}{|c|}{ Tobacco consumption in Smokers } \\
\hline Mean (SD)† & $13.50(1.63)$ & $0.01 \ddagger$ \\
\hline \multicolumn{3}{|l|}{ Age } \\
\hline Mean (SD)† & $39.40(1.43)$ & $0.17 \ddagger$ \\
\hline \multicolumn{3}{|l|}{ Gender } \\
\hline Male & $31.7 \%$ & $0.02^{*}$ \\
\hline Female & $68.3 \%$ & \\
\hline \multicolumn{3}{|c|}{ Maximum altitude reached (masl) } \\
\hline Mean (SD) † & $3601.40(780.18)$ & $<0.01 \ddagger$ \\
\hline
\end{tabular}

${ }^{*} \chi^{2}$ test.

‡Mann-Whitney U test.

†Quantitative variables were expressed in mean (SD).

masl, metres above sea level. biased towards underestimating the smoking prevalence. Despite this, the smoking prevalence of the travellers was quite similar to the Spanish general population $(22.8 \%$ and $30 \%$, respectively), but lower number of cigarettes smoked.

Face-to-face interviews may be able to collect a level of detail that an indirect interview (post-travel questionnaire) may not be able to. Because this could represent a potential bias, we conducted a sensitivity analysis, and no difference was described. Phone conversations may also be more able to collect truthful data compared with email, or induce more participation, but an equal number of people were interviewed by phone compared with email in each group. Hence, the information bias was minimised.

Our population consisted of urban dwellers coming from Barcelona city and surroundings, with probably similar local air pollution exposure. However, we have not considered the potential source of carboxyhaemoglobin exposure in families due to secondhand smoke or due to occupation exposure.

The specific causes and physiological mechanisms of AMS remain unclear.

Females were found to be more likely to experience AMS symptoms than males, maybe because they were taking oral contraceptives (OCPs) even though no statistical significance was observed, or depending on the day of their menstrual cycle, as the levels of progesterone vary throughout the different phases of the cycle. The high levels of circulating progesterone may increase resting ventilation and hypoxic and hypercapnic ventilatory responses; hence, it is considered as a respiratory stimulant. OCPs reduce the amount of circulating progesterone and might negate the preventive effects of acetazolamide use. $^{20}$

Because the exact time of exposure to altitude was unknown, the speed of onset could not be evaluated; nevertheless, the risk of suffering from AMS could be determined. 
Table 3 Crude and adjusted ORs for altitude mountain sickness incidence; mutivariate analysis. $(n=302)$

\begin{tabular}{lllll}
\hline & Crude OR & $\mathbf{9 5 \%} \mathbf{C l}$ & ${\text { Adjusted } \mathbf{O R}^{\star}}^{*}$ & $\mathbf{9 5 \%} \mathbf{C l}$ \\
\hline $\begin{array}{l}\text { Smoking status } \\
\text { Non-smoker }\end{array}$ & 1 (Ref) & & 1 (Ref) & \\
$\begin{array}{l}\text { Smokers } \\
\text { Gender }\end{array}$ & 0.51 & 0.28 to 0.89 & 0.54 & 0.31 to 0.97 \\
$\quad \begin{array}{l}\text { Male } \\
\text { Female }\end{array}$ & 1 (Ref) & & 1 (Ref) & \\
$\begin{array}{l}\text { Maximum altitude reached } \\
\leq 3400 \text { masl }\end{array}$ & 1.58 & 1.06 to 2.36 & 1.53 & 1.06 to 2.25 \\
$>3400$ masl & 1 (Ref) & & 1 (Ref) & \\
\hline
\end{tabular}

${ }^{*}$ Adjusted by age and the remaining variables in the left column.

masl, metres above sea level.

In previous studies, the type of association between smoking and AMS differed. Our results are consistent with some previous studies conducted by Wu $e t a l^{2}$ and You $e t \mathrm{al}^{14}$ in occupational or military cohort studies. In these studies, individuals were taken to very high altitudes (above $4000 \mathrm{masl}$ ), and the authors described smoking as a protective factor for AMS ( $R R=0.76$ and 0.55 , respectively), as found in a meta-analysis by $\mathrm{Xu} e t$ al (pooled OR $=0.71,95 \%$ CI 0.52 to 0.96$).{ }^{17}$ However, $\mathrm{Li}$ et $a l^{21}$ and Vinnikov $e t a t^{22}$ found smoking to be a risk factor ( $R R=1.11$ and $H R=1.9$, respectively) when studying occupational cohorts or climbers commuting to very high altitudes (above 4000 masl), results that were in line with those shown in the meta-analysis performed by Vinnikov et al (pooled $\mathrm{OR}=0.88,95 \%$ CI 0.74 to 1.05$){ }^{23}$

Wu et $a l^{2}$ studied Chinese male railroad workers who were hired to build the final phase of the Qinghai-Tibet railroad and gradually ascended from the lowlands up to 4500 masl. They observed that $39 \%$ of smokers had AMS in contrast with $51 \%$ of the non-smokers ( $p$ value $=0.08$ ). The team suggested that the impaired endothelial function in smokers might have diminished their capacity to produce nitric oxide, ${ }^{11}$ which is one of the main effectors of vasodilatation in hypoxic conditions and therefore one of the elements responsible for the acute symptomatology during fast ascents without acclimatisation.

Our results could be generalised to travellers from high to very high altitude zones, regardless of age, gender and type of ascent, but the impact might differ according to the specific smoking prevalence of the traveller's country of origin.

\section{CONCLUSION}

In conclusion, our results seem to elucidate some AMS risk factors for travellers that could help improve the pretravel counselling visit as well as the prescription of prophylactic medication. As expected, MAR is relevant to the risk of suffering AMS. The higher the altitude, the higher is the risk that the individual will suffer from AMS. Smoking status should be considered when assessing the AMS risk, and we believe more studies are needed to elucidate its role. Probably because of its influence on the blood's oxygen transport as well as through its effects on vasoconstriction, smoking is a protective factor for the onset of AMS. When interpreting this fact, the following must be considered: smoking is strongly addictive; it increases the risk of cardiorespiratory and other diseases such as cancer; it decreases the exercise capacity, and it poses a risk for others from secondhand smoke. The effect that smoking has on the AMS risk seems considerable, and its main importance resides in the adaptation and improvement of the current pretravel consultation general guidelines. Smoking should always be discouraged, but when a patient that either refuses to stop smoking or whose travel to high altitude zones is imminent, smoking should be considered a factor that influences the risk of suffering from AMS. Thus, it should influence the decision to prescribe and take prophylactic medication before trips to high altitude zones.

Acknowledgements We would like to thank the participants who contributed generously their time and information to this study.

Contributors CM-A and JMR were responsible for study design and statistical planning. AS-M and SM-R were responsible for data collection and data analysis. All authors were involved in manuscript preparation and revision.

Funding This research received no specific grant from any funding agency in the public, commercial or not-for-profit sectors.

Competing interests None declared.

Patient consent Obtained.

Ethics approval This study was approved by the ethical review board of the University Hospital of Bellvitge.

Provenance and peer review Not commissioned; externally peer reviewed.

Data sharing statement Access to original data is available by emailing the corresponding author, CMA.

Open Access This is an Open Access article distributed in accordance with the Creative Commons Attribution Non Commercial (CC BY-NC 4.0) license, which permits others to distribute, remix, adapt, build upon this work non-commercially, and license their derivative works on different terms, provided the original work is properly cited and the use is non-commercial. See: http://creativecommons.org/ licenses/by-nc/4.0/

(c) Article author(s) (or their employer(s) unless otherwise stated in the text of the article) 2017. All rights reserved. No commercial use is permitted unless otherwise expressly granted. 


\section{REFERENCES}

1. Bircher HP, Eichenberger U, Maggiorini M, et al. Relationship of mountain sickness to physical fitness and exercise intensity during ascent. J Wilderness Med 1994;5:302-11.

2. Wu TY, Ding SQ, Liu JL, et al. Smoking, acute mountain sickness and altitude acclimatisation: a cohort study. Thorax 2012;67:914-9.

3. Hackett PH, Roach RC. High-altitude illness. N Engl J Med 2001;345:107-14.

4. Hultgren HN, Medicine HA. High Altitude Medicine: Stanford: Hultgren Publications, 1997:53-91.

5. Bärtsch P, Gibbs JS. Effect of altitude on the heart and the lungs. Circulation 2007;116:2191-202.

6. Roach RC, Bartsch P, Hackett PH, et al. The Lake Louise acute mountain sickness scoring system. In: Sutton JR, Houston CS, Coates G, Hypoxia and Mountain Medicine: proceeding of the International hypoxia Symposium, 1993:272-4.

7. Hackett PH, Rennie D, Levine HD. The incidence, importance, and prophylaxis of acute mountain sickness. Lancet 1976;2:1149-55.

8. Burtscher M, Mairer K, Wille M, et al. Risk factors for high-altitude headache in mountaineers. Cephalalgia 2011;31:706-11.

9. Honigman B, Theis MK, Koziol-McLain J, et al. Acute mountain sickness in a general tourist population at moderate altitudes. Ann Intern Med 1993;118:587-92.

10. Schneider M, Bernasch D, Weymann J, et al. Acute mountain sickness: influence of susceptibility, Preexposure, and ascent rate. Med Sci Sports Exerc 2002;34:1886-91.

11. Burgess KR, Johnson P, Edwards N, et al. Acute mountain sickness is associated with sleep desaturation at high altitude. Respirology 2004;9:485-92

12. MacLean N. Smoking and acclimatisation to altitude. $\mathrm{Br}$ Med J 1979;2:799.
13. Wu TY, Ding SQ, Liu JL, et al. Who should not go high: chronic disease and work at altitude during construction of the Qinghai-Tibet railroad. High Alt Med Biol 2007;8:88-107.

14. You H, Li X, Pei T, et al. Predictive value of basal exhaled nitric oxide and carbon monoxide for acute mountain sickness. Wilderness Environ Med 2012;23:316-24.

15. Scherrer U, Rexhaj E, Jayet PY, et al. New insights in the pathogenesis of high-altitude pulmonary edema. Prog Cardiovasc Dis 2010;52:485-92.

16. Vinnikov D, Blanc PD, Steinmaus C. Is Smoking a Predictor for Acute Mountain Sickness? findings from a Meta-Analysis. Nicotine Tob Res 2016;18:1509-16.

17. Xu C, Lu HX, Wang YX, et al. Association between smoking and the risk of acute mountain sickness: a meta-analysis of observational studies. Mil Med Res 2016;3:37.

18. USGS. Earth Resources Observation Systems Data Center (EROSDC) (homepage on the Internetinternet). http://eros.usgs.gov (accessed Nov 2013).

19. Shuttle Radar Topography Mission Water Body Dataset (SRTM) (homepage on the internet). http://eros-usgs.gov/digitized-maps (accessed Nov 2013).

20. Regensteiner JG, Woodard WD, Hagerman DD, et al. Combined effects of female hormones and metabolic rate on ventilatory drives in women. J Appl Physiol 1989;66:808-13.

21. Li Y, Liu Y. Oxygen enrichment and its application to life support systems for workers in high-altitude areas. Int J Occup Environ Health 2014;20:207-14.

22. Vinnikov D, Brimkulov N, Blanc PD. Smoking increases the risk of acute mountain sickness. Wilderness Environ Med 2015;26:164-72.

23. Vinnikov D, Blanc PD, Steinmaus C. Is Smoking a Predictor for Acute Mountain Sickness? Findings From a Meta-Analysis. Nicotine Tob Res 2016;18:1509-16. 